\title{
Escenificar el archivo (hasta que el cuerpo aguante). Una lectura en torno a lo documental en Esto (no) es un testamento y Animales invisibles de La Laura Palmer
}

\author{
Staging the archive (until the body drops). A reading of the \\ documentary features found in Esto (no) es una testamento [This is (not) \\ a testament] and Animales invisibles [Invisible animals] by La Laura \\ Palmer \\ Javiera Larraín George \\ CONICYT - Pontificia Universidad Católica de Chile \\ javiera.larraing@gmail.com
}

\section{Resumen}

Este artículo plantea un análisis documental de las prácticas escénicas de archivo dispuestas en los montajes Esto (no) es un testamento y Animales invisibles de la compañía chilena La Laura Palmer. En consecuencia, se pretende indagar en las condiciones operatorias que administran y desmantelan la lógica archivística que los montajes proponen; a través de una revalorización de la colección de registros, objetos y testimonios que intentan poner en tensión los recuerdos privados e íntimos de los sujetos y el discurso oficialista de la memoria. Las prácticas artísticas - bajo esta óptica- se transforman en parte del archivo que La Laura Palmer busca explorar, con la intención de revisitar parte de los espacios institucionales que han forjado la Historia de la escena nacional chilena; en este caso la compañía de teatro ICTUS y el trabajo de los técnicos del emblemático Teatro Nacional Chileno.

Palabras clave: documento, archivo, memoria, teatro chileno, La Laura Palmer.

\begin{abstract}
This article aims to carry out a documentary analysis of the scenic archival practices used in the plays This (is not) a testament and Invisible Animals y the Chilean company La Laura Palmer. Consequently, it investigates the operating conditions that manage and dismantle the archival logic proposed by the plays. It does so through a revaluation of the collection of records, objects, and testimonies that bring tension to the private and intimate memories of the subjects and the official discourse of memory. Artistic practices - from this perspective- become part of the archive that La Laura Palmer explores, revisiting some of the institutional spaces that have forged the
\end{abstract}


History of the Chilean national theater scene; in this case, ICTUS theater company and the work of the technicians from the emblematic Chilean National Theater.

Keywords: document, archive, memory, Chilean theatre, La Laura Palmer.

"When to the sessions of sweet silent thought/ I summon up remembrance of things past,/ I sigh the lack of many a thing I sought,/ And with old woes new wail my dear times' waste:/ Then can I drown an eye, unus'd to flow,/ For precious friends hid in death's dateless night,/ And weep afresh love's long since cancell'd woe,/ And moan the expense of many a vanis'd sight".

Sonnet XXX, William Shakespeare ${ }^{1}$

Las construcciones y prácticas dramatúrgicas chilenas de la pasada década han articulado - en parte- sus estrategias escriturales desde la lógica del archivo; para así instalar una relación dialógica, con sus precursores, en torno a la crisis sobre el agotamiento de su propio entramado cultural. De este modo, se entreteje una relación operatoria de memoria archivistica ${ }^{2}$ en el teatro nacional; en la que es importante tener en consideración que la memoria del propio archivista - en este caso las figuras del dramaturgo y/o director- trabajarían más allá de las distancias de lo temporal y de lo espacial en relación a su contexto de producción local.

Es así que el teatro chileno post-2000 ha adoptado las figuras del archivo como una estética administrativa de sus procesos artísticos, donde se busca desmantelar el cómo un archivo funciona para exponer la potencia política con la que este opera en cierto circuito de la actualidad. Pero presuponer que esta sería la única

1 "Cuando a sesión de calmo pensamiento/ convoco los recuerdos del pasado/ la pérdida de antaño es lo que siento/ y el tiempo agoto en un pensar gastado;/ se arrasa mi ojo, casi siempre enjuto/ por amigos sepultos en la noche/ lloro otra vez con revivido luto/ de esfumadas visiones el derroche" (traducción de Miguel Ángel Montezanti, del 'Soneto XXX' de William Shakespeare).

2 Es importante mencionar que el giro archivístico, que -como sabemos- tuvo un gran impacto en el contexto de las artes visuales, también repercutió -y repercute- profundamente las prácticas escénicas. Si bien, el archivo - en un principio- ha sido entendido como un sitio de legitimización de la cultura; las excavaciones posmodernas de las materialidades propias del archivo recurren a sus contenidos para desmantelar sus estructuras, por lo que, en palabras de Marita Sturken: "gran parte del arte contemporáneo puede ser visto como un deliberado desarreglo de los archivos -institucionales, autoritarios, colonialesque fueron considerados una garantía bajo el modernismo" (en Tello 127). Me pregunto -por tantohasta qué punto el archivo, los testimonios o los documentos pueden circunscribirse a un nuevo modo de operación en el campo de las artes escénicas, y -por sobre todo- qué se entiende por archivo -y sus consecuentes desmantelaciones- en este contexto. 
manera en que los archivos son manejados a nivel creativo dentro de las puestas en escena; podría llevar a encadenar al archivo en las mismas lógicas de producción estáticas de las que este ha querido desentenderse. Aquí -por consiguienteentenderé que el archivo dentro de las artes escénicas: “antes que una metáfora, un insumo de la obra o un mero recurso estético, es más bien aquella disposición social que se manifiesta, o se visibiliza, por la subversión de una praxis política que busca desorganizar o alterar el ordenamiento ideal del corpus arcóntico que define nuestro presente" ('Tello 139).

Para realizar este cometido, el de activar operaciones en escena que cuestionen la exégesis de lo político, algunos autores y compañías han decidido trabajar desde la lógica operacional del archivo y la memoria con el fin -en ocasiones colaterales- de que el resabio de lo documental aparezca sobre escena de manera patente y honesta. Guillermo Calderón -por ejemplo- hace acopio de esta 'necesidad de realidad' en su penúltima obra, Mateluna (2016), la cual se basa en la injusta condena judicial del ex-frentista Jorge Mateluna, perteneciente al Frente Patriótico Manuel Rodríguez (FPMR), que actualmente se encuentra preso y condenado a dieciséis años de cárcel por un asalto bancario que no cometió, en la comuna de Pudahuel; en medio de una serie de irregularidades tanto de Carabineros como de la Fiscalía que estuvo a cargo de la investigación. Por su parte, la Compañía Colectivo Zoológico, articula su trabajo No tenemos que sacrificarnos por los que vendrán (2015) en torno a las Actas que la Biblioteca Nacional revelara en 2012 y que contienen los diálogos de los cinco días de reuniones que sostuvo la Junta Militar para reformar el código laboral, en 1979. Así, la obra realiza una especie de reenactment de las discusiones y alegatos auténticos entre los personajes reales que rearticularían la economía y las leyes laborales de este país hacia el neoliberalismo.

Sin embargo, la revisitación archivística de los hechos históricos de nuestro pasado reciente, no es la única aproximación afectiva documental ${ }^{3}$ que ha propuesto la escena local. En este panorama, el trabajo de la Compañía La Laura Palmer ${ }^{4}$

3 Entender la práctica documental -en artes escénicas- desde una inflexión afectiva, no busca mermar la inclusión de la memoria histórica; sino más bien, intenta establecer un enlace epistemológico en donde la percepción de los documentos no sea exclusivamente cognitiva, sino que pueda darse también desde lo sensorial. Es así que la inflexión afectiva busca cuestionar dentro de las lógicas artísticas de lo documental: "To what extent does the writing historian's own subjectivity -conceived as social, cultural, textual, personal, or (most crucially) historical- affect the construction of the past as object?" (Rosen 85). 4 Conformada actualmente por los artistas Pilar Ronderos (1988) e Itallo Gallardo (1984), ambos actores egresados de la Universidad de Chile. En un comienzo, Gallardo junto con el actor Jorge Arecheta (1984) inician su trabajo -en La Laura Palmer- el 2008 con el estreno de la obra Nosotros; para proseguir con los trabajos La espera (2010) y Doblevé cé (2011). Pero es en la obra Juan Cristóbal, casi al llegar a Zapadores (2012) que ocurre un punto de inflexión dentro de la Compañía, volcándose por completo a 
- con más de una década de vida-destaca no sólo por su constante labor en torno a las prácticas escénicas ligadas al documento y a la autobiografía, sino que también por su revalorización del devenir histórico del teatro chileno como una sinécdoque de la Historia nacional. El presente artículo - por defecto- plantea un análisis alrededor de la lógica documental de trabajo en torno a sus producciones Esto (no) es un testamento (2017) y Animales invisibles (2019). Estas obras se edificarían desde la revisión biográfica de aquellos personajes que han forjado la historia de la escena chilena desde la diversidad de sus oficios (actores, diseñadores, técnicos y directores), para, asimismo, poner en valor desde la práctica teatral, los acontecimientos políticos que como sociedad nos han llevado hasta nuestro presente actual.

una exploración y profundización del lenguaje documental dentro de sus siguientes producciones: Limites (2014), Los que vinieron antes (2016), Hija de tigre (2016), Amanecerá con escombros en el suelo (2019), Exbumación. Ensayo performático sobre Isidora Aguirre (2019) y las dos piezas que conforman el presente estudio. A largo de la historia de la Compañía, Ronderos y Gallardo han trabajado con una serie de artistas y colaboradores, entre ellos: Laurène Lemaitre, Nicole Senerman, Mónica Drouilly y Roberto Collío. 
"I look at people like building. Instead of walls and rooms, we have stories and experiences. As long as we can live these stories, express these stories, tell and retell these stories, then we can stand up, the way a building stands".

Kutlug Ataman, Interview with Ana Finel Honigman (2004)

\section{Chile, lindo país esquina con vista a una compañía teatral}

Esto (no) es un testamento

Para Rebecca Schneider el cuerpo de los actores puede ser leído como un archivo: "The actions and choices of artists that precede you are part of your own legacy, and those past actions and endeavors rebuckle and bend in your hands -life you know what you are doing. Without any past there is precious little juice for the future (Theatre 29)". A partir de esta premisa, se estructura el montaje Esto (no) es un testamento, coproducción del Centro Cultural Gabriela Mistral y la Compañía ICTUS, ${ }^{5}$ en colaboración con La Laura Palmer. Estrenada a finales de junio de 2017, la obra recorre la trayectoria del ICTUS a través de tres de sus integrantes actuales: María Elena Duvauchelle, Paula Sharim y José Secall, quienes revisan interpelados constantemente por la audiovisualista Nicole Senerman- sus vidas teatrales y personales, desdibujando los límites entre ambas.

La obra no se plantea sólo como un homenaje, también busca instalarse como una reflexión que intenta poner en tensión -al igual que otras piezas de La Laura Palmer- la manera en que se construye el relato de la Memoria. De esta forma, cada uno de los integrantes del ICTUS presentes en este montaje recordará importantes momentos de su biografía personal. En el caso de José Secall, su estadía

5 La compañía ICTUS se funda en 1955, y es una de las compañías chilenas -activas hasta la fechade más larga data en Chile. En la historia teatral nacional, ICTUS buscó potenciar -en sus inicios- los espacios de creación colectiva e improvisación, no sólo en la construcción de sus puestas en escena, sino también en la conformación de un modelo de gestión y administración. En sus casi 70 años de trayectoria, es posible identificar cuatro etapas fundamentales dentro de su desarrollo histórico: [1] 1955-1960: fundación de la Compañía, a partir de un grupo de alumnos escindidos del Teatro de Ensayo UC; [2] 1960-1967: recambio de creadores, ingreso de actores formados en la U. de Chile, con experiencia profesional en el Teatro de la U. de Concepción, la compañía se instala en la Sala La Comedia, en pleno Santiago Centro; [3] 1968-1988: se afianza el método de producción de la Compañía a través de la creación colectiva, muchas veces en conjunto con los dramaturgos en la adaptación de sus obras; y [4] 1989-a la fecha: cambio socio-económico de paradigma nacional, ICTUS comienza a explorar nuevos formatos, autorías y lenguaje en pos renovar la vigencia de sus propuestas (Canales, Harcha y Martínez). 
como exiliado en Moscú y la historia de separación con su familia ("Decido volver a Chile, y seguir luchando a pesar de que eso significaba separarme de mi hija Adela y de Viviana" [Esto (no) 27]); o en el de María Elena Duvauchelle, la muerte de su hermano ("Me dicen que Héctor, mi hermano, está muerto ... escapamos de la muerte en Chile y la encontramos allá" [26-27]); o en el de Paula Sharim, su lucha para distanciarse de la figura de su padre en pos forjar su propia carrera profesional ("Con el teatro en la sangre y en la vida. No tengo complejo de ser la hija de Nissim" [41]; "Sé que vinieron a verme porque soy hija de él” [43]). A su vez, se incluyen algunas intervenciones remotas digitales de Nissim Sharim, quien por medio de una serie de contactos telefónicos ingresará a escena -como un fantasma virtual- para esclarecer algunos espacios de fricción en la memoria dentro del devenir histórico del ICTUS.

Por consecuencia, el montaje se erige - por una parte- desde una vinculación documental afectiva; y -por otra parte-como una interpretación experiencial de la historia de los últimos sesenta años de nuestro país. En este sentido, las historias personales de los sujetos que habitan esta Compañía se convierten en constructos escénicos que metonímicamente intenta mapear una identidad nacional. A este respecto, para Stuart Hall: "Identity is always in part a narrative, always in part a kind of representation. It is always within representation. Identity is not something which is formed outside and then we tell stories about it. It is that which is narrated in one's own self" (49). Ronderos y Gallardo, comprenden -consiguientemente- que no existe una identidad teatral nacional, sino un conjunto de escenarios hipotéticos donde se construyen historias, como las vividas por los integrantes que han conformado el ICTUS en sus sesenta y cinco años de trayectoria.

Ambos directores, organizan una puesta en escena que dialoga -y contraposiciona- la condición material e inmaterial del archivo. A lo largo del montaje, los actores manipularán una serie de cajoneras predispuestas en un mueble que funciona como fondo escenográfico (diseñado por Laurène Lemaitre), componiendo el escenario de sus propias vidas bajo la atenta mirada de la cámara (distanciador modélico y narrativo) operada en vivo por Nicole Sernerman. Pero la prolijidad técnica con la que se manipulan estos artilugios manuales no descansa en una mera espectacularidad ornamental, ya que la obra pretende distinguir las condiciones del archivo de aquello a lo que se le reduce con frecuencia: la experiencia de la memoria y el retorno al origen (arcaico) del recuerdo. Para ello: "no sólo se requiere que el archivo esté depositado en algún lugar, sino que exista [en] un lugar de autoridad" (Guasch 166). Esto (no) es un testamento, en la negación camuflada de su propio título, anuncia una declaración frente a esta condición; no en el cuestionamiento del lugar 
de consignación arcóntico de los archivos, ${ }^{6}$ sino en la interpretación afectiva de los mismos. En varias de sus intervenciones, María Elena Duvauchelle evidencia un quiebre en la construcción del relato oficial de la Compañía, cuando indica la controversia que significó su salida de ICTUS durante el proceso de ensayo de Tres noches de un sábado, en donde a sólo dos semanas del estreno sufre una pielonefritis y es marginada del montaje:

NISSIM. Yo no me acuerdo de eso. La memoria es selectiva, uno se acuerda de lo que debe acordarse.

MELENA. A mí lo que me parece insólito es que Nissim no se acuerde que me echaron del grupo.

PAULA. Bueno, eso es cierto. Porque te aseguro papá... Y no mirí pa arriba cuando te hablo... Te aseguro que si el enfermo hubiera sido uno de los hombres, no habría pasado lo mismo. ...

NISSIM. Seguramente, no... Pero no es algo que me llene de orgullo. (Gallardo \& Ronderos 15-6).

La organización del relato de la memoria oficial, aquella que contaron los miembros de la Compañía, se opone al recuerdo individual de María Elena, que termina por deslegitimizar la organización del discurso historiográfico de sus compañeros, situación que se evidencia en las tímidas disculpas de Nissim Sharim ("Era otra época", "hoy no sería lo mismo" [16]). Desde un punto de vista formal, en esta pequeña disputa: "La constante de [la configuración del] archivo corre, además, pareja al debate reciente sobre la historia/memoria como una manera no sólo de cuestionar las nociones de pasado sino, ... de constatar una crisis fundamental en la manera de imaginar futuros alternativos" (Guasch 164). La disposición documental de los insumos (fotografías, notas de ensayo, apuntes) se transforman en piezas que no sólo componen el archivo, sino que también ayudan a cuestionarlo.

Igualmente, la obra reflexiona sobre la propia configuración de la Compañía, consignada en la historia nacional como un grupo humano que privilegió la crea-

6 El sentido arcóntico del archivo (en griego: arkheîn; una casa, un domicilio, la residencia de los magistrados) ostenta el poder que poseen los documentos oficiales y da cuenta de la competencia hermeneútica en torno a los mismos: su interpretación. Como afirma Derrida: "La consignación tiende a coordinar un solo corpus en un sistema o una sincronía en la que todos los elementos articulan la unidad de una configuración ideal" (19). En la obra, la constitución de los archivos -ya sea materiales o inmateriales- que son expuestos, evidencia que estos han sido custodiados desde un lugar de consignación; encapsulada en la figura de Sharim y en algunos de los miembros emblemáticos de la Compañía (Guzmán, Salcedo, Contreras). 
ción colectiva por sobre los personalismos individuales. Pese a ello, es curioso que el montaje decide - precisamente- instalar la centralidad del relato en tan sólo unos pocos miembros de la Compañía; incluyendo a otros miembros importantes de este grupo sólo desde la mención documental (fotografías, precisiones historiográficas), pero no desde la construcción del relato memorístico del mismo. En escena, María Elena Duvauchelle señalará: “En 1972 ya estábamos trabajando en la idea de la creación colectiva ... A esa altura Julio Jung ya se había ido, protestando porque la Delfina y Nissim se comportaban como patrones de fundo y diciendo que la compañía se terminaría llamando 'Sharim/Guzmán'. Pero yo me quedé” (Gallardo \& Ronderos 9). Esta acotación considera la memoria - en sentido figurado- como un registro que delega la responsabilidad de recordar y -hasta cierto punto- de interpretar el archivo: "Modern memory is firts of all archival. It relies entirely on the specificity of the trace, the materiality of the vestige, the concreteness of the recording, the visibility of the image" (Nora 62).

Pero, al mismo tiempo, la obra se presenta como una construcción a pequeña escala de los hitos históricos que marcaron la segunda mitad del siglo XX en Chile, siendo, evidentemente, la Dictadura un punto tangencial dentro de la historiografía del ICTUS. El 11 de septiembre de 1973, cada uno de los actores recordará ese día no sólo desde una mera mención anecdótica, sino desde la convicción del entendimiento que una parte de sus vidas se acaba para siempre ("MELENA. Entonces empezamos a escuchar los aviones que pasan por encima, se escucha el bombardeo y a lo lejos se ve una nube de humo. Una parte importante de mi vida se borraba con esa nube" [Gallardo \& Ronderos 20]; "PEPE. Desde esa noche entendimos que nuestros días ya no serían los mismos. La noche había llegado para quedarse" [20]). A la vez, la obra propondrá que el ICTUS, tanto los integrantes de la Compañía como el inmueble físico del teatro que la cobija, se convertirán en un pertrecho de resistencia contra la Dictadura. Es así que se recuerdan, principalmente, tres montajes que marcaron este período: Tres noches de un sábado, La noche de los volantines y Primavera con una esquina rota. Este último montaje adquiere una relevancia importante dentro de la obra puesto que en 1985, durante la realización de una de sus funciones, el actor Roberto Parada -quien era parte del elenco original- se entera del asesinato de su hijo José Manuel, en el llamado 'Caso degollados':?

7 El caso Degollados, es el nombre con el que se conoce al secuestro y asesinato de tres miembros del Partido Comunista de Chile (Santiago Nattino Allende, Manuel Guerrero Ceballos y José Manuel Parada Maluenda) perpetrado por Carabineros hacia finales de la dictadura militar de Augusto Pinochet. Nattino sería secuestrado el 28 de marzo de 1985; mientras que Guerrero y Parada, lo serían un día después, ambos secuestros se realizaron a plena luz del día y en presencia de numerosos testigos. La brutalidad del asesinato perpetrado por agentes del Estado remeció a la sociedad chilena de la época. En la actualidad, sólo uno de los seis miembros del servicio secreto de la policía, que fueran condenados a 
PAULA. El 29 de marzo de 1985, en esta misma sala, estaba ocurriendo una función de la obra PRIMAVERA CON UNA ESQUINA ROTA. Don Roberto Parada era el protagonista de esta obra y su hijo, José Manuel Parada, había sido secuestrado el día anterior.

MELENA. Entre el $1^{\mathrm{er}}$ y el $2^{\circ}$ acto, llega la hija de Roberto al teatro a avisar que habían encontrado el cuerpo de José Manuel.

PEPE. Sus compañeros de escena no saben muy bien qué hacer. Nissim le dice al público que la obra se va a suspender y desde camarines se escucha la voz de Roberto diciendo: ‘La obra no se detiene! La obra continúa, en homenaje a mi hijo asesinado por chacales que el mismo chacal rechazaría'.

MELENA. Se había juntado un montón de gente afuera del teatro. Al terminar la función, se armó una enorme fila y uno por uno fueron subiendo al escenario a abrazar a Roberto ...

PEPE. Algunos textos tomaron nuevo significado. Un ejemplo de ello era el texto que Rafael, el abuelo interpretado por el tío Roberto, decía en la escena que acabamos de hacer: 'Cuando revientan a un militante, como fue el caso de mi hijo y arrojan a su familia al exilio involuntario... ¡Desgarran el tiempo! ¡Trastruecan la historia! No sólo para ese mínimo clan, sino que corrompen los cimientos de toda la sociedad' (32-3).

El sentido de la obra, había cambiado totalmente. De una manera macabra casi perversa- la ficción teatral se había adelantado a la Historia y -como señala Paula- había usurpado la vida de uno de los actores, traicionando su propia naturaleza (33). Los documentos que acompañan este relato (fotografías, textos del montaje, recortes de diario), si bien se construyen a partir de la memoria individual de quienes lo organizan, dejan de ser 'memorias individuales'; para erguirse como un lenguaje afectivo emocional que edifica nuestra Historia (Dyens 78).

En Esto (no) es un testamento, pareciera que el teatro se vuelve un refugio, una fortaleza que aloja los fantasmas de nuestra memoria, que atesora los documentos de nuestra Historia, y que condena a sus guardianes (los actores, los sobrevivientes) a una absoluta soledad. Tal como recuerda José Secall, al rememorar a sus antiguos compañeros de escena en La noche de los volantines (Edgardo Bruna y Héctor Noguera); ayudado por María Elena y Paula, realizará una suerte de reenactment que contrapone la materialidad del archivo documental (la grabación de la obra original) con la performance actual que lo tiene como único sobreviviente de dicho montaje.

cadena perpetua en 1994 por este caso, cumple condena efectiva. 
Esta escena demarcará la sensibilidad vital que sostiene la lectura archivística que realiza La Laura Palmer en torno al ICTUS: esta obra no puede ser un testamento, negando la propia legalidad ontológica del archivo. Y no puede serlo, no porque no posea documentos que la avalen; sino porque, al igual que el ICTUS y las memorias fantasmales que todavía lo habitan, esta obra aún no está preparada para morir. 
"La historia de la sala de espectáculos no es sino el derrotero de estos dos núcleos en cambiante movimiento, cada una dando forma y sentido a la otra. A través de los tiempos, público y actores, hijos de diferentes épocas, se enfrentarán de modos distintos: condiciones económicas, regímenes políticos diferentes. Evoluciona la sociedad y el teatro con ella. Cada época aporta diversas necesidades que dan forma a sus propias condiciones dramáticas, definidas cada una por su edificio teatral”.

Escenografía teatral, Guillermo Núñez

\section{Tras los bastidores de la resistencia}

\section{Animales invisibles}

Si En (esto) no es un testamento, la lectura archivística de los vestigios documentales del ICTUS eran un impulso -una lucha- que buscaba oponerse a la desaparición del olvido; Animales invisibles se instala desde los bastiones de la derrota. La obra -estrenada en agosto de 2019- indaga en la biografía personal y escénica de siete técnicos del Teatro Nacional Chileno $(\mathrm{TNCH}),{ }^{8}$ quienes durante décadas colaboraron en la cimentación de la Sala Antonio Varas como uno de los espacios teatrales más importantes en nuestra historia escénica nacional. El montaje los sitúa en una posición que, hasta el momento, nunca habían experimentado: la de protagonistas, ya que como bien señala la actriz Nicole Waak, quien recibe al público y funge como una médium que nos conecta a otra dimensión: "nos centraremos en los espíritus de los que hicieron mover los engranajes de este teatro desde lo subterráneo. Los que nunca se subieron al escenario a brillar" (Gallardo \& Ronderos 2). Ellos son: Guillermo Gangas Martínez (diseñador y jefe técnico), Fernando Boudón (tramoyista), Silvio Meier Hertz (director de escena), Carlos Moncada (luminotécnico), Camilo Retamal (utilero), Sebastián Chávez (asistente técnico) y Joaquín Riquelme (operador de sonido).

El montaje juega a ser dos obras dentro de una. La primera, se presenta como una especie de homenaje póstumo, reconocimiento tardío de una vida dedicada al

8 El 10 de noviembre de 1954 estrenó Noche de Reyes de Shakespeare, dirigida por Pedro Orthous en la Sala Antonio Varas, la que se convertiría en la sede definitiva del Teatro Experimental de la Universidad de Chile, creado en 1941. Los cuatros objetivos fundamentales que perseguía -en sus orígenes- en TNCH fueron: la difusión del teatro clásico y moderno, la formación de una escuela de teatro, la gestación de un público teatral y la presentación de nuevos valores teatrales en todos sus ámbitos. Hoy en día, la administración de las dependencias del teatro, están a cargo de la Facultad de Artes de la Universidad de Chile. 
teatro desde las sombras. Con sólo alrededor de cuarenta y dos espectadores, Nicole invita al público a un viaje por el tiempo y divide a la audiencia en seis grupos. Cada uno de ellos, ingresará por turnos alternos a los camarines del mítico Teatro Nacional Chileno; y en cada uno de estos habitáculos se encuentra un espejo que deberá ser encendido por alguno de los miembros del grupo, para iluminarse -por medio de un artilugio de grabación espejeada- con el rostro de alguno de nuestros mártires escénicos, hombres de teatro que -en la ficción de la obra- dieron su vida por un oficio que los ha olvidado ("Ahora que ya no estoy en este plano de realidad, me gustaría que me recordaran como una persona que quiso crear cierta humanidad en el teatro" [4]; "Yo ya no estoy ahí físicamente para poder hacerlo. Y, ¿sabe por qué? Porque me resistí a ver morir este teatro" [5]; "El teatro se hace con todos los que aportan a crear una ilusión. Y los técnicos hacen esa labor, pero no reciben aplausos" [7]; "Ir perdiendo el trabajo me hizo ir perdiendo la vida" [10]). Además, es posible apreciar una cantidad asombrosa de utensilios, objetos, fotografías, afiches, dibujos, libretas; en fin, registros que materializan la visualidad de cada uno de sus oficios.

Los camarines - bajo el diseño de Catalina Devia- se homologan a animitas teatrales que no sólo recuerdan a los fallecidos técnicos, también glorifican sus perdidos oficios, que en la actualidad de un teatro más inmediato y en las dinámicas culturales del consumo neoliberal, no tienen cabida. El artilugio de sus saberes ocurría bajo las condicionantes de una temporalidad que hoy no existe, en donde el tiempo no se monetizaba; y las dinámicas alrededor de la manofactura se definían como procedimientos pulcros y precisos ("Nunca improvisé cuando hice un guion de luces" [4]; "siempre existió un desprecio por el trabajador manual ... yo todo lo hice con mis manos y estoy orgulloso de eso" [7]; "Mi cargo consistía en coordinar toda la maquinaria teatral para una función. Fui esclavo del reloj. El tiempo fue mi campo de batalla ... Hice de mi oficio un rito" [9]). De la misma manera, se evidencia la arqueología de una ocupación extinta, que llega a carcomer el cuerpo de sus trabajadores ("¡Mire mis manos! Tengo marcas en las manos. Marcas del paso del tiempo, marcas que me dejó el paso de la corriente a través de mi cuerpo" [11]); y se señala una ética laboral9 en apariencia caduca a los

9 El trabajo de diseño, realizado por Catalina Devia, en el foyer del teatro marca la escala valórica y el lugar de enunciación ético en que se yergue el montaje. En uno de los espejos se transcribió parte del Manifiesto Artístico del artista visual Guillermo Núñez (1930): "Yo aprendí del teatro mi visceral necesidad dramática. Mi pintura tuvo en el espacio teatral, en su poesía, el apoyo seminal para empezar a hablar. Ese espacio engendra tiempo y yo quiero usarlo demencialmente como un arma en mis búsquedas. Espacio y tiempo. Tiempo y poesía. Hacer de la imaginación una verdad poderosa. Unir tu propia locura a la de otros locos como tú: una comunidad, un universo de hombres y mujeres que, devotos, generosos, van buscando, llenos de amor, ser parte de un milagro siempre único, un misterio que nace, irrepetible, cada 
modelos de dirección cultural actuales ("Aún no puedo olvidar ese día que llegué a trabajar y ya no había nada de las cosas que habíamos guardado por años. Habían exterminado el lugar" [14]).

Al terminar este periplo por un tiempo de antaño, la audiencia es guiada fuera de los camarines por Nicole hacia los propios bastidores tras el escenario, y es invitada a sentarse en los escasos puestos designados para los vivos, ya que gran parte de las butacas tienen nombre y apellido, ocupadas por aquellos fantasmas que ya no se encuentran entre nosotros (Víctor Jara, Malú Gatica, Agustín Siré, Isidora Aguirre, Pedro Mortheiru, entre muchos otros). Aquí, comienza una segunda obra, una pequeña ficción que emula una reunión en el subsuelo, entre nuestros antiguos homenajeados, que se lamentan de la crítica situación administrativa que afecta al Teatro Nacional Chileno.

Los reflejos póstumos del equipo técnico y artístico que han operado las maquinarias de uno de los escenarios más importantes de nuestra escena nacional, disponen frente a los espectadores la problemática de la 'desaparición documental' en torno al registro de las artes escénicas: ¿Cómo archivar las variaciones técnicas entre cada función? ¿Cómo registrar la naturaleza efímera de la performance de un intérprete? ¿Cómo escapar del 'fetichismo archivista' que busca encapsular la ‘singularidad del presente momentáneo' del acto teatral? Para Rebecca Schneider: "Performance does not disappear when approached from this perspective, though its remains are the inmaterial of live embodied acts. Rather, performance plays the 'sedimented acts' and spectral meanings that haunt material in constant collective interaction, in constellation, in transmutation" (Performing 102). Bajo esta consigna, el montaje dirigido por Ronderos y Gallardo, repara en el hecho de que, aunque una obra desaparezca, no es sinónimo de que esta no deje vestigios. ${ }^{10} \mathrm{El}$ teatro, de esta manera, se transforma en una ruina repleta de restos que estarían a

vez que un actor, una actriz, y otros fantasmas, entre sombras y luces logran unir sala y escena, público y poeta. Este espacio imaginario que la poesía, la obra, ha creado, y que el juego de los actores se ha encargado de hacer audible con su cuerpo, con su voz, ha podido ver la luz, ser real por una orquesta invisible: maquinistas, utileros, traspuntes, sastres y sastras, iluminadores, directores y el escenógrafo que han querido dar forma a esta realidad diferente que, muchas veces, es todavía una nebulosa en el autor. La obra, su poesía, es el motor que ha hecho nacer el respeto mutuo con que estos mundos vivirán esta aventura. Toda la imaginación, las ideas, las teorías, búsquedas y caprichos, dogmas, fanatismos, obsesiones, deben servir a un solo propósito. Actores y servidores invisibles, unidos para inclinarse con amor, antes lo más importante la obra y su autor. Un universo".

10 Cabe destacar la relación que se establece -en esta obra- entre archivo y sacrificio. Para que la vida de los técnicos del Teatro Nacional se vuelva objeto de documento, su existencia material debe ser borrada. Hay -provocadoramente- un vínculo entre performance y muerte: "Killing the autor, or sacrificing his station, may be, ironically, the means of ensuring thejat he remains" (Schneider, Performing 103). 
la espera de ser documentados y recordados para no caer en las fauces del olvido. La puesta en escena de Animales invisibles se articula desde esta contradicción en la que: "death appears to result in the paradoxical production of both disappearance and remains" (102). Una vez más, las figuras - en gran parte- anónimas de la escena chilena se han sacrificado a sí mismas, puesto que sólo con la pérdida física de sus cuerpos, afloran los vestigios materiales de sus antiguos oficios: "a loss that the archive can regulate, maintain, institutionalize -while forgetting that it is a loss that the archive produces" (103). De hecho, esta es la crítica medular que unifica ambas partes del montaje: la desaparición de los oficios olvidados de estos cuerpos teatrales proviene de la misma transformación fundacional del teatro, vale decir, la institucionalidad ha convertido en material de archivo la funcionalidad de quehaceres que -hoy por hoy- consigna como obsoletos.

Durante el transcurso de la obra se establece una crítica operacional a las lógicas que rigen el teatro actual, amparadas desde las condicionantes del consumo y las leyes del mercado. Además, se constituye una relación de nostalgia con estos oficios del pasado que -cual animales en peligro de extinción- se encuentran prontos a desaparecer. Cada uno de los testimonios nos permite conocer no sólo cómo se producía el teatro de antaño -aquel mítico período de los Teatros Universitarios-; sino que también nos posibilita comprender cómo ocurría la cadena de producción jerárquica en que se creaba una obra (dirección, actuación, diseño, manufactura, operación).

Pero, a diferencia de Esto (no) es un testamento, en Animales invisibles se pervierte el testimonio documental, al proponer espacios de ficción que chocan con la supuesta oficialidad archivística. Sin ir más lejos: "The Spectator is not in need of signpost and inverted commas to understand that a documentary is a negotiation between reality on the one hand and image, interpretation and bias on the other. Documentary is predicated upon a dialectical relationship between aspiration and potential" (Bruzzi 6). Gallardo y Ronderos -en la primera parte de la obra- dan cuenta de una filiación subjetiva con los materiales, documentos y testimonios que podrían conformar un archivo sobre el Teatro Nacional Chileno (una promesa documental). ${ }^{11}$ Entienden que la elaboración del mismo descansa -al unísonoen un poder simbólico que está fuera de los subsuelos donde se encuentran los

11 Permítaseme una aclaración del término. En palabras de Janelle Reinelt: "The promise of documentary at this levek is to stablish a link between spectators' quest and an absent acknowledged reality. If we want to understand the minimal claim of the documentary, it is simple facility: the indexical value of documents is the corroboration that something happened, that event took place" (11-12). Descansaría en la configuración del montaje, consecuentemente, una promesa documental en torno a la encarnación del cuerpo de los técnicos con los objetos que les pertenecieron. 
técnicos ("Los de arriba son los que están en el segundo piso del teatro. Tienen oficina, privilegios y son quienes dan órdenes. Los de abajo son los que trabajan realmente, los que se encargan del escenario y son el sustento de este teatro" [15]). Así, en la segunda parte del montaje se establece una crítica a las condiciones de operatividad dentro de las lógicas de consumo neoliberal actuales (trabajadores sin contrato, sueldos bajos, atrasos en los pagos), que consideran el mantenimiento del Teatro Nacional Chileno como un gasto, un lastre que se resiste a morir. La crítica al modelo administrativo es directa, olvidando todos los velamientos que con anterioridad operaban en los camarines. La discusión se subdivide en dos nodos de tensión principales: el primero de ellos descansa en la comparativa con las prácticas profesionales en que se trabaja en el teatro antes de los tiempos del capitalismo descarnado; mientras que el segundo se sitúa en una crítica directa -y sin ningún tapujo- a las prácticas del Director actual del teatro en el momento de realización de la temporada del montaje. En ambas discusiones, es interesante rescatar que el personaje/performer de Guillermo Gangas se presenta como un detonante de conflicto, al mostrarse reticente en mirar con nostalgia la forma de creación procesual de los Teatros Universitarios ("Ese teatro clásico a mí me genera aversión, es como un logotipo. Era la forma en la que se suponía que se tenía que montar una obra” [26]; “Ese teatro clásico hecho a la clásica, es un imaginario súper retrógrado!" [27]), y en no compartir una crítica tan feroz a la administración actual ("pero yo los veo tan angustiados a ustedes... Y yo se lo he dicho a los cabros acá, cuando uno está mal en el trabajo, lo mejor es hacerse a un lado" [39]).

No obstante existan diferencias entre ellos, hay un acuerdo común en entender que la forma en que se comprende y produce el teatro ha cambiado y -distintamente a lo que planteaban los integrantes del ICTUS- no ha sido entera responsabilidad del período de la dictadura, ya que la decadencia del TNCH que se denuncia ocurre en el transcurso de la democracia:

[1] SILVIO. Bueno es que eso era antes po’ weón, con la dictadura vino un apagón cultural, iy después de eso quedó la cagá!

CAMILO. Ahí rebato un poquito. Nosotros con la democracia empezamos a joder. Se terminaron las revistas: La Análisis, La Apsi. Los milicos le ponían recursos al teatro, y Hernán Letelier podía montar grandes obras. El mercader de Venecia, Otello, La Gaviota, Juan Tenorio.

CARLOS. Si po es que le daban esos recursos porque querían aparentar que había cultura.

CAMILO. Pero cuando llegó la democracia, cagamos po (25); 
[2] WILLY. ¿'Oye y Letelier implantó en el teatro el sistema neo liberal? CAMILO. ¡Pero si Letelier estuvo del 75 al 81 no más! (27);

[3] WILLY. Pero es que, ¿sabes cuál es la diferencia? ... ¡Antes había un largo trabajo previo al primer ensayo!

BOUDÓN. ¿Pero por qué no habrá tiempo?

WILLY. ¡Por una cosa de plata pos Fernando, si de eso es lo que estamos hablando! (28);

[4] SILVIO. Bueno ¿Y qué hacemos con todo esto chiquillos? Los directores están sordos, la Facultad hace vista gorda de nuestro problema, la gente de afuera nos ve sólo de manera romántica... Y ni siquiera saben cómo estamos...

CAMILO. Si supieran que cuando llegó este Director nos botó todo lo que habíamos guardado por años... Fue como si hubiese botado una parte de nosotros...

CARLOS. Como si hubiesen botado una parte de la Historia de este teatro... (40).

Los diálogos que suceden entre los técnicos en el subsuelo del teatro establecen un relato de alteridad en torno a la memoria institucional (deudora del TNCH); y -en cierta medida- se sitúan desde el desecho de la memoria privada de los des-acuerdos que el consenso oficialista de la Transición promovió (Richard 29). De esta suerte, el archivo se vale para interpretar y borronear los testimonios que no modelen parte de su repertorio convenido y que sean catalogados como inconvenientes, ${ }^{12}$ pero: "es la laboriosidad de esta memoria insatisfecha, que no se da nunca por vencida, la que perturba la voluntad de sepultación oficial del recuerdo mirado simplemente como depósito fijo de significaciones inactivas" (30). Inclusive, en la falta de acuerdo entre los técnicos frente a las polémicas que discuten, se evidencia una aversión al consenso entendido - parafraseando a Moulian- como la etapa superior del olvido. Si se considera la memoria como un proceso continuo de

12 Para Richard: "el consenso político es sólo capaz de 'referirse a' la memoria (de evocarla como tema, de procesarla como información), pero no de practicarla ni tampoco de expresar sus tormentos. 'Practicar' la memoria implica disponer de los instrumentos conceptuales e interpretativos necesarios para investigar la densidad simbólica de los relatos; 'expresar sus tormentos' supone recurrir a figuras del lenguaje (símbolos, metáforas, alegorías) suficientemente conmovibles para que entren en relación solidaria con la desatadura emocional del recuerdo" (31). El teatro documental de Gallardo y Ronderos, trabaja -en efecto- desde la liberación afectiva del archivo, entendiendo la memoria como una práctica instrumental, pero también emotiva; y es en esta última configuración donde se tejerían las contradicciones en torno al desmantelamiento de los archivos oficiales. 
reinterpretación del pasado, esta vendría a remecer la condición estática de algunos archivos. Gallardo y Ronderos aventuran una operación que intentaría remecer el pluralismo y el consenso propios del discurso de la democracia conciliadora, que es -en gran medida- foco de crítica entre los viejos técnicos.

Frente a la certeza de su inminente desaparición, los técnicos del Teatro Nacional Chileno deciden dar una última batalla y llevar sus demandas hacia el Palacio de la Moneda, situado a escasos metros de la Sala Antonio Varas. Todos se unen al llamado de su líder espontáneo, Silvio Meier; salvo Guillermo Gangas, quien solamente, luego de ser conminado por Fernando Boudón, se une a las tropas armadas con utilerías y vestuarios de guerra, en la última afronta del antiguo Teatro Nacional Chileno. Una grabación audiovisual se proyecta en la pantalla del escenario, ahora vacío de fantasmas. En ella vemos a los técnicos caer bajo los golpes de la policía y una secuencia final nos revela que a pesar de sus diferencias, Guillermo y Silvio caen juntos defendiéndose mutuamente de los golpes incesantes de las fuerzas del orden. Si la muerte viene por ellos, que los lleve a todos juntos; tal vez en un afán de sentirse menos solos. Como espectadores, la última imagen que vemos es la de una espada de utilería que cae y se pierde en un fade negro, que oscurece la sala de teatro y hace desaparecer por siempre aquellos oficios objetuales y materiales de las artes escénicas de nuestra pasada Historia, y que la contingencia cultural neoliberal ha destinado al olvido.

La ficción se completa con la caída de estos cuerpos maltrechos y cierra el círculo significativo de presentarlos en un comienzo como fantasmas. Aunque -bien sabemos- ninguno de estos seis hombres ha muerto; pero la dramaturgia y la dirección deciden situarlos desde dicho lugar, porque sólo la voz de los muertos es capaz de remecer la estaticidad de un archivo fosilizado por la institucionalidad. La forma del simulacro viene al rescate del contenido de los recuerdos, siendo necesaria la mentira de la ficción (la trampa) para proteger la verdad.

\section{El cuerpo como documento: tensionar el archivo}

Simone Osthoff señala que:

When artists perform the archive, and artists' archives are exhibited as art installations; when the mass media is used as a medium for art making and exhibitions re-enact historical event by seamlessly combining documentary and fiction; when the past refuses to settle and nature's entropic processes are countered by a generative technology designed to upgrade and perpetuate itself -is history permanently undead? (43-44). 
Dicha inquietud es trabajada -más allá de algunas distinciones enunciativaspor La Laura Palmer en estas dos obras. A diferencia de sus montajes anteriores (Los que vinieron antes o Hija de tigre), los procedimientos documentales en Esto (no) es un testamento y Animales invisibles se trasladan desde la autobiografía hacia los espacios interseccionales del recuerdo personal (Heddon 21) y hacia la representación polémica en torno a la interpretación del archivo. Gallardo y Ronderos comprenden que asumir la ecuación de equivalencia entre 'testimonio' y 'verdad', hace olvidar que la experiencia está siempre velada por la estructura del lenguaje; y es sólo por medio del lenguaje donde cualquier documento y archivo puede adquirir valor. Para ambos creadores: "In the field of performance, the act of representing the self perhaps resonates somewhat differently, since in place of the absent self which all self-referential writing unavoidable figures, the spectator is confronted rather by the physically present self" (27). Así pues, el cuerpo encarnado de la historia teatral, no pretende desmantelar -únicamente- las condiciones operativas en que funcionan los documentos que componen un archivo; también intenta desmantelarse a sí mismo, al poner en duda la propia condición de verdad de su acto enunciativo. La Laura Palmer al formular que el propio cuerpo es factible de devenir en archivo, sitúa necesariamente a la historia teatral y a la reproductibilidad técnica en torno a esta, como una práctica colaborativa.

Desde una intuición documental, Gallardo y Ronderos buscarían liberar a las prácticas del archivo de la cultura melancólica que ha sido impuesta por el arte contemporáneo en torno a su materialidad retórica (Foster 22). Los cuerpos de aquellos actores y artesanos anónimos que siguen resistiendo en ambas obras, ya sea frente o tras bambalinas, proveen de memoria narrativa al archivo nacional de nuestras artes escénicas; y sus narrativas secundarias sólo adquieren coherencia al evitar la nostalgia lectiva que el romanticismo de la cultura de consumo quisiera imponer sobre estos cuerpos: la inmovilidad. Por ello, el gesto común de abandonar el teatro con el que cierran ambas obras, no es fortuito. En el caso del ICTUS, las cajoneras con los documentos que contienen su Historia son predispuestos a lo largo del escenario; y en el caso de los técnicos del Teatro Nacional Chileno, estos marchan a La Moneda a luchar una última batalla. Abandonar el teatro y dejar a los espectadores solos frente al escenario permite entender que el valor material de un archivo escénico existe en carne viva, sólo cuando hay cuerpos que lo habiten. Estos dos desenlaces guardan en común una relación fantasmagórica y -cuasi- metafísica. ¿Nuestros aplausos frente a un escenario vacío existen si es que nadie puede escucharlos? La ilusión teatral con que cierran estos montajes - presentando salas de teatro vacías- pareciera ser un eco mortuorio y una crítica 
TEATRO RECIENTE EN CHILE Y ARGENTINA: DOCUMENTO, VIOLENCIA Y POLÍTICA

descarnada, tanto a la comprensión de las prácticas de archivo en el arte, como a las lógicas de gestión y consumo cultural que borronean los cuerpos y los saberes desgastados frente al imperio neoliberal de lo inmediato. 


\section{Obras citadas}

Bruzzi, Stella. New Documentary: A Critical Introduction. London: Routledge, 2006.

Canales, Rodrigo; Harcha, Ana \& Martínez, Angélica. "ICTUS en la década de los 80". CD-ROM: Chile, 1948-1988. Los teatros independientes en escena. Historia crítica y memoria audiovisual. Sección II. "Cartografías. 23 compañías de teatro independiente chileno". Programa de Investigación y Archivos de la Escena Teatral, Pontificia Universidad Católica de Chile, Santiago.

Derrida, Jacques. Mal de archive: una impresión freudiana. Madrid: Trotta, 1997.

Dyens, Ollivier. “The Sadness of the Machine // 2001”. Memory. Ian Farr (ed.). London: The MIT Press, 2012: 75-79.

Foster, Hall. "An Archival Impulse”. October 110 (2004): 3-22.

Gallardo, Italo y Ronderos, Pilar. Animales Invisibles, 2019. Inédito. . Esto (no) es un testamento, 2017. Inédito.

Hall, Stuart. "The Local and the Global: Globalization and Ethnicity". Culture, Globalization and the World-System: Contemporary Conditions fot he Representations of Identity. A.D. King (ed.). London: Macmillan, 1991: 19-39.

Heddon, Deirdre. "Politics (of Self): The Subject of Autobiography". Autobiography and performance. London: Palgrave Macmillan, 2008: 20-52.

Gausch, Anna Maria. Arte y Archivo, 1920-2010. Genealogias, tipologías y discontinuidades. España: Akal, 2015.

Moulian, Tomás. "El consenso". Chile actual: anatomía de un mito. Santiago: Arcis/ LOM, 1997: 37.

Nora, Pierre. "Reals of Memory // 1984". Memory. Ian Farr (ed.). London: The MIT Press, 2012: 61-66.

Osthoff, Simone. "When Documentation and Memory Refuse to Settle is the Archive Alive?" Performing the Archive: The Transformation of the Archive in Contemporary Art from Repository of Documents to Art Medium. New York: Atropos Press, 2009: 45-59.

Reinelt, Janelle. "The Promise of Documentary". Get Real. Documentary theatre past and present. Alison Forsyth and Chris Megson (eds.). London: Palgrave Macmillan, 2011: 6-23.

Richard, Nelly. "Políticas de la memoria y técnicas del olvido". Residuos y metáforas. (Ensayos de critica cultural sobre el Chile de la Transición). Santiago: Cuarto Propio, 2001: 27-73. 
TEATRO RECIENTE EN CHILE Y ARGENTINA: DOCUMENTO, VIOLENCIA Y POLÍTICA

Rosen, Philip. "Document and Documentary: On the Persistence of Historical Concepts". Theorizing Documentary. Michael Renov (ed.). London: Routledgw, 1993: 58-89.

Tello, Andrés Maximiliano. "El arte y la subversión del archivo". Aisthesis $\mathrm{N}^{\circ} 58$ (2015): 125-143.

Schneider, Rebecca. Performing Remains. Art and war in time of theatrical reenactment. London: Routlegde, 2001.

. Theatre \& History. London: Palgrave Macmillan, 2014. 